\title{
EDITORIAL
}

\section{Editorial changes}

\author{
Thomas L. Slovis
}

Received: 5 June 2009 / Accepted: 5 June 2009 / Published online: 20 June 2009

(C) Springer-Verlag 2009

Stephen Chapman is stepping down after $61 / 2$ years as a managing editor of Pediatric Radiology. His administrative duties at Birmingham Children's Hospital have been significantly increased and all are additive to his role as Chief of Pediatric Imaging leaving much less time for his editorship.

Steve and I became managing editors at the same time in 2003. We came with the same goals of a unified (not part American, part European), high-quality journal that publishes the majority of pediatric radiology articles each year. We sought to do this in a very timely manner. We jointly built the Editorial Board. We jointly developed minisymposia and educational supplements and expanded the breadth of the journal. Our monthly issues now average over 100 pages, increased from the 75 when we took over.
Steve developed the popular section Hermes, and it was his idea to publish the annual courses of the ESPR and SPR in the meeting supplements so that all subscribers receive the benefit of these excellent educational endeavors.

The last $6 \frac{1}{2}$ years have been a true partnership in crafting a "single journal" and giving our readers a unified approach. I will miss Steve, his superb knowledge base, sense of humor, and dedication. Fortunately, Steve will stay on the Editorial Board and will continue to give us his new ideas and, if necessary, appropriate criticism. He will continue with Hermes.

Guy Sebag has been selected and agreed to become managing editor. He has been an associate editor since 2003 and managed minisymposia on inflammatory bowel disease and fetal MRI. Guy is an accomplished pediatric expert in MR. I welcome my new partner.

T. L. Slovis $(\triangle)$

Department of Pediatric Imaging,

Children's Hospital of Michigan,

3901 Beaubien Blvd.,

Detroit, MI 48201, USA

e-mail: pedradeditor@med.wayne.edu 